\title{
Avaliação do estado nutricional de seringais implantados na região da Zona da Mata de Minas Gerais ${ }^{(1)}$
}

\author{
Ciríaca Arcangela Ferreira de Santana do Carmo ${ }^{(2)}$, Neli do Amaral Meneguelli(2), \\ Jorge Araújo de Sousa Lima ${ }^{(2)}$, Paulo Augusto da Eira(2) e Tony Jarbas Ferreira Cunha(2)
}

\begin{abstract}
Resumo - O objetivo deste trabalho foi avaliar o estado nutricional de seringais implantados na Zona da Mata, em Minas Gerais, visando contribuir com um programa racional de adubações. Em seringais do clone IAN 873 foram determinadas a classe do solo, fertilidade, nutrição e produção de borracha seca. Grande parte dos seringais encontra-se em Latossolos extremamente ácidos com Al alto e N, P, K, soma de bases trocáveis e capacidade de troca de cátions baixos. Os teores de Ca e $\mathrm{Mg}$ variaram de médios a altos nos Latossolos e foram muito altos nos Nitossolos, correlacionando-se negativamente com a produção de borracha seca. A análise foliar detectou desequilíbrios nutricionais no que se refere aos baixos teores de $\mathrm{N}$ e K evidenciados pela correlação positiva significativa com a produção de borracha seca. A correlação significativa negativa entre a produção de borracha seca e os teores de Ca foliares, associados aos altos teores de $\mathrm{Mg}$, sugerem a redução desses nutrientes nas adubações. Dos micronutrientes, apenas o $\mathrm{Cu}$ apresentou correlação positiva e significativa com a produção de borracha seca.
\end{abstract}

Termos para indexação: Hevea brasiliensis, diagnose foliar, necessidade de nutriente, adubação, nutrição vegetal.

\section{Nutritional evaluation of rubber tree plantations at Zona da Mata region, Minas Gerais State, Brazil}

\begin{abstract}
The objective of this work was to evaluate the nutritional status of rubber tree plantations at Zona da Mata region, Minas Gerais State, Brazil, to contribute with fertilization programs. Soil class, fertility levels, nutritional state and production of dry rubber were determined in rubber plantations of the clone IAN 873. Most plantations occur over extremely acid Oxisols with high contents of $\mathrm{Al}$ and low values of $\mathrm{N}, \mathrm{P}, \mathrm{K}$, sum of exchangeable basis and cation exchange capacity. Calcium and $\mathrm{Mg}$ contents varied from medium to high and showed negative correlation with dry rubber production. Plant analysis showed unbalanced contents of $\mathrm{N}$ and $\mathrm{K}$ with low values but positive and significant correlation with dry rubber production. Significant and negative correlation between dry rubber production and $\mathrm{Ca}$ contents, associated to high contents of $\mathrm{Mg}$, showed that these nutrients may be reduced in fertilization schemes. Copper was the only micronutrient that showed a significant correlation with dry rubber production, and it was positive.
\end{abstract}

Index terms: Hevea brasiliensis, leaf diagnosis, nutritional requirements, fertilizing, plant nutrition.

\section{Introdução}

A avaliação do estado nutricional de plantas conjuga as análises de solo e de tecido vegetal (geralmente folha) permitindo, de maneira eficaz, a identificação de desequilíbrios nutricionais e dos nutrien-

\footnotetext{
(1) Aceito para publicação em 25 de abril de 2002.

(2) Embrapa-Centro Nacional de Pesquisa de Solos, Rua Jardim Botânico, 1024, CEP 22460-000 Rio de Janeiro, RJ E-mail: ciriaca@cnps.embrapa.br,neli@cnps.embrapa.br, jorge@cnps.embrapa.br, eira@cnps.embrapa.br, tony@cnps.embrapa.br
}

tes mais limitantes à produção agrícola, além do que serve de base para recomendação de adubação. Essa técnica assume primordial importância no caso da seringueira que, por se tratar de cultura perene, de ciclo muito longo, necessita, em todas as fases de seu desenvolvimento, de um correto programa de adubação.

O levantamento do estado nutricional para recomendação de um programa de adubação em seringais é um procedimento bastante utilizado nos países produtores de borracha (Bataglia et al., 1988). Na Malásia, esta indicação é respaldada na análise do solo, da planta, do conhecimento da classe 
taxonômica do solo, assim como, das exigências nutricionais específicas dos diversos clones (Guha \& Narayanan, 1969).

No Brasil, os estados tradicionalmente produtores de borracha utilizam a análise de solo e o histórico da área como indicadores da situação do estado nutricional dos seringais e das recomendações de adubação. Entretanto, nas áreas não tradicionais, a análise de solo e o diagnóstico foliar têm sido utilizados na avaliação e acompanhamento de programas de adubação, possibilitando um significativo retorno e melhoria da qualidade das recomendações (Bataglia et al., 1999).

Os teores de nutrientes nas folhas nem sempre apresentam correlação direta com os teores disponíveis no solo, uma vez que outros fatores, como umidade, aeração, compactação, acidez e doenças de raízes, também afetam a absorção de nutrientes pelas plantas (Raij, 1981).

Vários autores estabeleceram faixas de concentração de nutrientes nas folhas, consideradas adequadas ao bom desenvolvimento da seringueira, acima e abaixo da qual a planta pode apresentar excesso ou deficiência de determinado nutriente. Beaufils (1957), em estudos pioneiros de nutrição de seringueira, estabeleceu um método, baseado no diagnóstico fisiológico, que permite determinar as relações de equilíbrio entre os diversos nutrientes, dois a dois, independentes do solo, do local e do material genético. Posteriormente, Bolton (1964) verificou que essas relações eram inadequadas para diagnosticar as necessidades nutricionais em seringais, na Malásia, pois as relações de N, P e K, consideradas em equilíbrio nos plantios do Vietnã, não se mostraram equilibradas para garantir uma produção satisfatória nos seringais da Malásia.

Assim é que Bataglia et al. (1988), avaliando a situação do estado nutricional de 40 seringais produtivos, no Estado de São Paulo, estabeleceram faixas de concentrações de nutrientes, que ocorrem na maioria desses seringais com diferentes níveis de produtividade. Verificaram que aqueles que apresentavam alta produtividade (acima de $1.000 \mathrm{~kg}$ de borracha seca/ha) mostravam, também, concentrações mais elevadas de $\mathrm{N}$ e K nas folhas. Os autores constataram maior desenvolvimento da seringueira em solos com melhor nível de fertilidade sendo que os baixos níveis de $\mathrm{P}$, nas folhas e nos solos, estariam afetando a produtividade. Estes resultados foram ratificados por Bataglia et al. (1999).

Em Minas Gerais, notadamente na região da Zona da Mata, a heveicultura apresenta características peculiares em relação à expansão da cultura, pois a região, além de não ter tradição neste setor de exploração agrícola, apresenta elevada diversidade ambiental em relação à fertilidade do solo, à topografia, aos aspectos fundiários e de uso agrícola. Além disso, não existem informações sobre as exigências nutricionais dos clones cultivados, nem sobre a adubação mais adequada.

O objetivo deste trabalho foi diagnosticar e avaliar a situação do estado nutricional de seringais, na região da Zona da Mata de Minas Gerais, visando contribuir com um programa racional de adubação.

\section{Material e Métodos}

A região estudada situa-se a, aproximadamente, $20^{\circ} 30^{\prime}$ de latitude Sul e $43^{\circ} 0^{\prime}$ de longitude Oeste, com altitude média de 500 metros. A temperatura média máxima anual é de $21,8^{\circ} \mathrm{C}$ e a mínima de $19,5^{\circ} \mathrm{C}$, com precipitação média anual de $1.250 \mathrm{~mm}$. Segundo a classificação de Köppen (Setzer, 1946), o clima da região varia do tipo Cwa, tropical úmido a Aw, semi-úmido de verões quentes. A vegetação anterior à implantação dos seringais, era em grande parte constituída de pastagem degradada e de cafezais decadentes.

O trabalho foi realizado em 25 seringais de cultivo, implantados na região da Zona da Mata, no Estado de Minas Gerais. Utilizou-se o clone IAN 873, com aproximadamente 14 anos de idade, localizado nos Municípios de Leopoldina (3), Cataguases (8), Muriaé (4), Oratórios (4) e Raul Soares (6). As determinações e caracterizações realizadas abrangeram a parte pedológica, fertilidade e aspectos nutricionais das plantas. As amostragens foram realizadas em fevereiro, nos anos de 1997 e 1998.

Dentro dos seringais, escolheram-se, aleatoriamente, parcelas compostas de 42 plantas, com 16 plantas úteis, de onde coletaram-se amostras de solo e de folhas. Por meio de entrevistas com os produtores e preenchimento de questionários, foram levantadas informações sobre histórico, manejo e produtividade das áreas, esta última confirmada via documentação de venda de látex. Os seringais avaliados utilizam o sistema de sangria de $1 / 2 \mathrm{~S} \mathrm{~d} / 2$, com cerca de 140 sangrias/ano, e estimulação com Ethefon, na concentração de $2,5 \%$. 
Para caracterização dos solos, foram coletadas amostras nas profundidades de $0-20 ; 20-40 ; 40-60 ; 60-80$ e $80-100 \mathrm{~cm}$, fora da zona de aplicação de fertilizantes, uma amostra composta por área. A caracterização dos solos foi realizada segundo Embrapa (1979), Camargo et al. (1987) e Lemos \& Santos (1996) e a classificação dos solos com base na interpretação dos resultados analíticos, foi realizada segundo Embrapa (1999). As análises químicas seguiram as normas preconizadas pela Embrapa (1979) e consideraram a composição granulométrica, argila dispersa em água, grau de floculação, $\mathrm{pH}(1: 2,5)$ em água e $\mathrm{KCl} 1 \mathrm{~N}$, complexo sortivo $\left(\mathrm{cmol}_{\mathrm{c}} \mathrm{dm}^{-3}\right): \mathrm{Ca}^{2+}, \mathrm{Mg}^{2+}, \mathrm{Na}^{+}, \mathrm{K}^{+}, \mathrm{S}, \mathrm{T}$, $\mathrm{V} \%, \mathrm{Al}^{+3}, \mathrm{H}^{+}, \mathrm{P}$ disponível $\left(\mathrm{mg} \mathrm{dm}^{-3}\right)$, segundo Vettori (1969).

A amostragem de solo, para fins de fertilidade, foi efetuada nas linhas e entrelinhas da parcela útil, em três profundidades de 0-20, 20-40 e 40-60 cm, e retirada uma amostra composta, por profundidade. As análises químicas foram realizadas conforme Embrapa (1997) e, no caso do enxofre, segundo Vitti (1989). Os dados de fertilidade foram interpretados conforme o recomendado pelo Instituto da Potassa \& Fosfato (1998) e Comissão de Fertilidade do Solo do Estado de Minas Gerais (1999).

O diagnóstico do estado nutricional das plantas foi realizado por meio da análise química de folhas coletadas das 16 plantas úteis da parcela segundo o método preconizado por Bataglia et al. (1988). A determinação dos teores de macro e micronutrientes foi realizada segundo Silva (1999).

$\mathrm{Na}$ ausência de definição dos teores adequados dos macro e micronutrientes, em relação ao bom desenvolvimento da seringueira, nas condições do Estado de Minas Gerais, optou-se por interpretar os resultados das análises foliares, segundo as relações de Beaufils (1957): N/P- normais: 12,7-16,1; tendência ao desequilíbrio: 10,8-12,6 e 16,2-18,0 e fortemente desequilibradas: $<10,8$ e $>18,0$; N/K- normais: $3,4-4,3$; tendência ao desequilíbrio: 2,9-3,3 e 4,4 - 4,8; fortemente desequilibradas: <2,9 e >4,8; K/P - normais: 3,4-4,3; tendência ao desequilíbrio: 2,9-3,3 e 4,4-4,8 e fortemente desequilibradas: $\langle 2,9$ e $>4,8$; S/Pnormais: $0,8-1,2$; tendência ao desequilíbrio: $0,5-0,7$ e 1,3-1,5 e fortemente desequilibradas: $<0,5$ e $>1,5$ e segundo as faixas adequadas de concentração de macro e micronutrientes elaboradas por Murbach (1997): em $\mathrm{g} \mathrm{kg}^{-1}$ : N, 26,0-35,0; P, 1,5-2,3; K, 10,0-15,0; Ca, 7,5-11,0; Mg, 1,7-4,3; S, 1,2-2,4; em mg kg-1: Fe, 73-441; Mn, 45-1034; Cu, 9-19; Zn, 15-51; B, 20-52.

Foram realizadas análises de regressão linear e correlação simples entre a produção de borracha seca e os teores de nutrientes no solo, nas profundidades de 0-20, 20-40 e 40-60 cm; e a produção de borracha seca e os teores de nutrientes nas folhas.

\section{Resultados e Discussão}

Por causa da alta similaridade dos resultados analíticos de solo e da produção de borracha seca encontrados nas amostragens realizadas nos dois anos, optou-se por considerar apenas as médias das duas coletas.

Nas áreas estudadas, cerca de $76 \%$ dos solos foram identificados como pertencentes às classes dos Latossolos Vermelho-Amarelos e $24 \%$ às dos Nitossolos Vermelhos, ambos sob relevo ondulado ou forte ondulado. Os Latossolos caracterizam-se por serem distróficos e ácricos e os Nitossolos, distróficos e eutróficos. As duas classes de solo apresentam horizonte diagnóstico superficial A moderado e textura variando de argilosa a muito argilosa. Os Latossolos ocupam a maior parte das encostas e do topo das colinas, enquanto os Nitossolos, o terço inferior e o sopé das encostas.

Apesar dos menores teores de nutrientes verificados nos Latossolos (Tabela 1), verifica-se uma melhor performance na produção de borracha seca (Figura 1), decorrente provavelmente de menores restrições físicas ao desenvolvimento do sistema radicular, minimizando os efeitos do período seco prolongado, que caracteriza o clima da região. Resultados semelhantes foram encontrados por Cunha et al. (2000).

Setenta e seis porcento destas áreas apresentaram acidez ativa extremamente elevada, com $\mathrm{pH}$ abaixo de 4,5 e os restantes $24 \%$, acidez mediana. As correlações entre a produção de borracha seca e o pH do solo, nas três profundidades, foram negativas e significativas, ou seja, à medida em que o pH aumenta, a produção da seringueira diminui (Tabela 2). Os teores de Al trocável situaram-se na faixa de $44 \%$ alto, $48 \%$ médio e apenas $8 \%$ baixo, assim como a acidez potencial $(\mathrm{H}+\mathrm{Al})$, em torno de $40 \%$ alta, que decresceu à medida que a profundidade aumentou. Provavelmente, estes atributos não afetaram o desenvolvimento da seringueira uma vez que, freqüentemente, a cultura é encontrada em Latossolos de baixa fertilidade natural e elevada acidez, o que revela bem a adaptação dessa cultura a esse tipo de solo. Assim, Pereira \& Pereira (1986), em seringais implantados em solos com $\mathrm{pH}$ variando entre 4,0 e 5,0 e altos teores de $\mathrm{Al}$ trocável, 
Tabela 1. Composição química média dos solos cultivados com seringueira, clone IAN 873, na Zona da Mata em Minas Gerais (média dos anos de 1997 e 1998).

\begin{tabular}{|c|c|c|c|c|c|c|c|c|c|c|c|c|}
\hline $\begin{array}{l}\text { No de } \\
\text { seringais }\end{array}$ & $\begin{array}{l}\text { Prof. } \\
(\mathrm{cm})\end{array}$ & $\begin{array}{c}\mathrm{pH} \\
\text { água } \\
\end{array}$ & $\begin{array}{c}\mathrm{P} \\
\left(\mathrm{mg} \mathrm{dm}^{-3}\right)\end{array}$ & $\mathrm{Ca}^{2+}+\mathrm{Mg}^{2+}$ & $\mathrm{K}^{+}$ & $\begin{array}{r}\mathrm{Al}^{+3} \\
\mathrm{nmol}_{\mathrm{c}} \\
\end{array}$ & $\begin{array}{l}\mathrm{H}+\mathrm{Al} \\
\left.\mathrm{m}^{-3}\right)----\end{array}$ & SB & CTC & $\begin{array}{c}\mathrm{V} \\
(\%)\end{array}$ & $\begin{array}{c}\mathrm{C} \\
---\left(\mathrm{g} \mathrm{kg}^{-1}\right.\end{array}$ & $\begin{array}{l}\mathrm{N} \\
1)--- \\
\end{array}$ \\
\hline \multicolumn{13}{|c|}{ Latossolo Vermelho-Amarelo ${ }^{(1)}$} \\
\hline 11 & $0-20$ & 4,2 & 1,2 & 5,1 & 0,5 & 9,1 & 56,6 & 5,6 & 62,2 & 9,4 & 10,7 & 1,2 \\
\hline & $20-40$ & 4,1 & 1,0 & 4,0 & 0,2 & 9,3 & 53,1 & 4,2 & 57,3 & 7,6 & 8,1 & 1,0 \\
\hline & $40-60$ & 3,4 & 1,0 & 3,5 & 0,2 & 8,2 & 47,1 & 3,7 & 50,8 & 7,6 & 6,8 & 0,8 \\
\hline \multirow{4}{*}{8} & \multicolumn{12}{|c|}{ Latossolo Vermelho-Amarelo $^{(2)}$} \\
\hline & $0-20$ & 4,0 & 1,0 & 3,4 & 0,6 & 10,7 & 59,8 & 4,0 & 63,8 & 6,6 & 10,4 & 1,1 \\
\hline & $20-40$ & 4,0 & 1,0 & 2,4 & 0,3 & 10,9 & 52,2 & 2,7 & 54,9 & 4,8 & 7,8 & 0,9 \\
\hline & $40-60$ & 3,5 & 1,0 & 2,1 & 0,2 & 9,9 & 47,0 & 2,3 & 49,3 & 4,6 & 6,0 & 0,9 \\
\hline \multirow{4}{*}{2} & \multicolumn{12}{|c|}{ Nitossolo Háplico ${ }^{(3)}$} \\
\hline & $0-20$ & 4,8 & 1,5 & 10,0 & 0,9 & 3,5 & 58,0 & 10,9 & 68,9 & 14,2 & 13,2 & 1,2 \\
\hline & $20-40$ & 4,7 & 1,0 & 5,5 & 0,3 & 4,5 & 38,0 & 5,8 & 43,8 & 13,1 & 6,9 & 0,7 \\
\hline & $40-60$ & 4,9 & 1,0 & 6,0 & 0,1 & 1,0 & 29,0 & 6,1 & 35,1 & 17,7 & 4,6 & 0,5 \\
\hline \multirow{4}{*}{2} & \multicolumn{12}{|c|}{ Nitossolo Vermelho $^{(4)}$} \\
\hline & $0-20$ & 5,2 & 1,0 & 19,0 & 1,3 & 3,5 & 42,0 & 20,3 & 62,3 & 29,8 & 10,2 & 1,1 \\
\hline & $20-40$ & 5,2 & 1,0 & 17,5 & 0,6 & 2,0 & 30,0 & 18,1 & 48,1 & 32,5 & 6,6 & 0,7 \\
\hline & $40-60$ & 5,6 & 1,0 & 15,5 & 0,4 & 1,0 & 22,0 & 15,9 & 37,9 & 41,0 & 4,7 & 0,5 \\
\hline \multicolumn{13}{|c|}{ Nitossolo Vermelho ${ }^{(5)}$} \\
\hline \multirow[t]{3}{*}{2} & $0-20$ & 5,3 & 2,5 & 35,5 & 1,8 & 1,0 & 40,0 & 37,3 & 77,3 & 47,9 & 15,3 & 1,3 \\
\hline & $20-40$ & 4,9 & 1,0 & 14,0 & 2,5 & 2,5 & 36,0 & 14,3 & 52,5 & 28,6 & 6,6 & 0,9 \\
\hline & $40-60$ & 4,8 & 1,0 & 12,0 & 0,3 & 3,0 & 36,0 & 12,3 & 48,3 & 25,1 & 6,7 & 0,8 \\
\hline
\end{tabular}

${ }^{(1)}$ Distrófico, típico, A moderado, álico, relevo forte ondulado. ${ }^{(2)}$ Ácrico, típico, A moderado, álico, relevo forte ondulado. ${ }^{(3)}$ Distrófico latossólico, A moderado, álico, relevo ondulado. ${ }^{(4)}$ Distrófico latossólico, álico, relevo ondulado. ${ }^{(5)}$ Eutrófico latossólico, A moderado, álico, relevo forte ondulado.

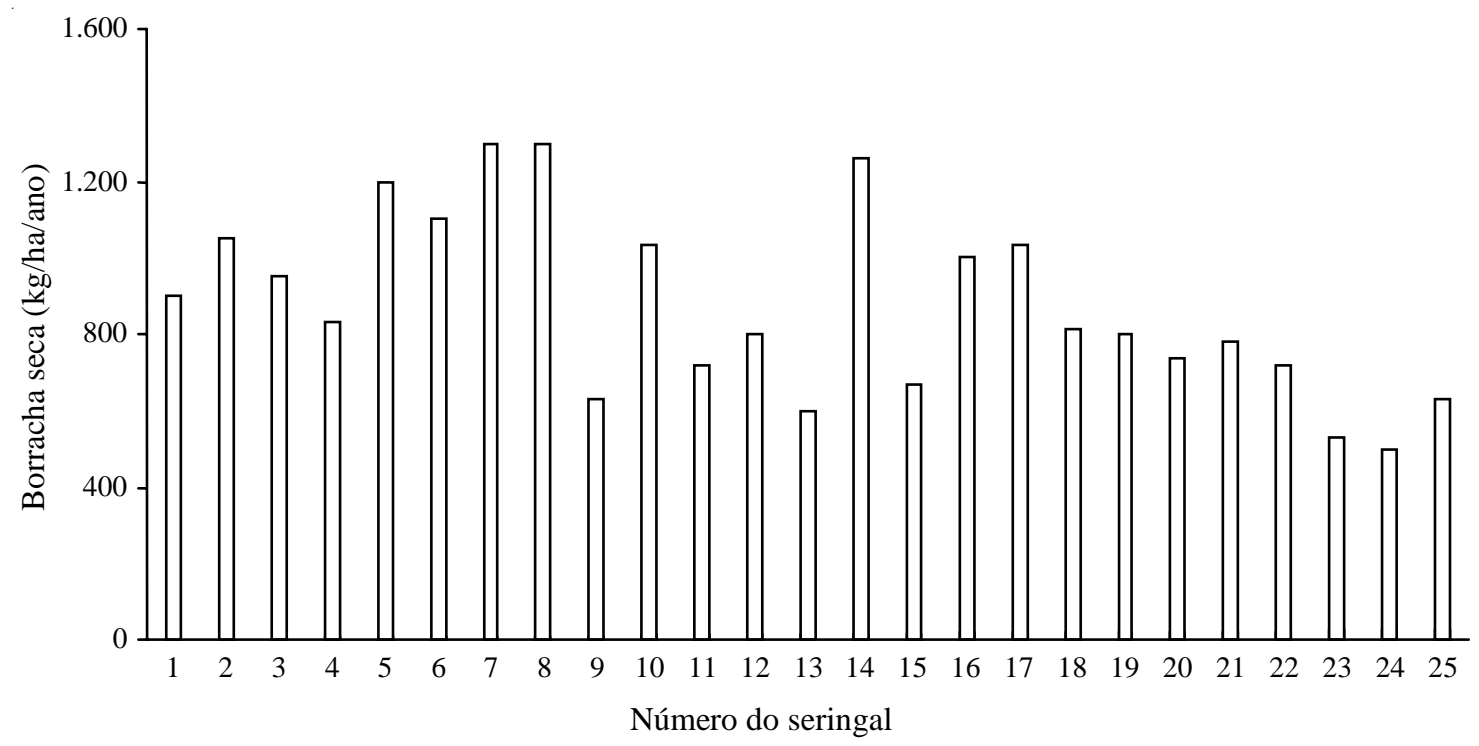

Figura 1. Produção média de borracha seca (kg/ha/ano) de 25 seringais do clone IAN 873, implantados na Zona da Mata de Minas Gerais (anos de 1997 e 1998). Seringais de 1 a 19 em Latossolos Vermelho-Amarelos e de 20 a 25 em Nitossolos. 
não observaram danos ao bom desenvolvimento das plantas. Kitamura (1992), em experimento de adubação com N, P, Ke Mg, em Latossolo VermelhoEscuro, no Município de Camapuã, MT, verificou que durante todo o período de coleta de dados (cinco anos), o pH do solo permaneceu em torno de 4,0, sem prejuízo ao crescimento das plantas. Segundo o autor, a seringueira supera o efeito adverso da acidez elevada por possuir um sistema radicular muito desenvolvido.

Todos os solos dos seringais avaliados apresentaram baixos teores de N, P e K disponíveis, nas três profundidades (Tabela 1). Falcão (1996) e Murbach (1997) enfatizam a importância do K como o principal responsável pelo crescimento e produtividade da seringueira, em solo arenoso de Marília, SP. Bataglia et al. (1998), na mesma classe de solo, observaram efeitos significativos das adubações nitrogenadas e fosfatadas no perímetro do caule e das adubações nitrogenadas e potássicas na porcentagem de plantas aptas à sangria. Resultados semelhantes foram obtidos por Bataglia et al. (1999) em seringais, em solo Podzólico Vermelho-Amarelo eutrófico, em Matão, SP, ressaltando não só a importância do K na nutrição da seringueira, como também no equilíbrio entre o N, o P e o K.

Os teores de $\mathrm{Ca}^{2+}+\mathrm{Mg}^{2+}$ variaram de médio a alto, em todos os solos dos seringais estudados, à exce-

Tabela 2. Equações de regressão e coeficientes de correlação (r) entre a produção de borracha seca $(\mathrm{Y})$ e as características químicas do solo $(\mathrm{X})$, nas profundidades de 0-20, 20-40 e 40-60 cm, de seringais do clone IAN 873, implantados na região da Zona da Mata de Minas Gerais.

\begin{tabular}{lcc}
\hline Variáveis & \multicolumn{1}{c}{ Equação } & $\mathrm{r}$ \\
\hline \multicolumn{3}{c}{$0-20 \mathrm{~cm}$} \\
Borracha seca x pH & $\mathrm{Y}=1.856,35-224,42 \mathrm{X}$ & $-0,56^{* *}$ \\
Borracha seca x Ca + Mg & $\mathrm{Y}=974,78-10,97 \mathrm{X}$ & $-0,51^{* *}$ \\
Borracha seca X SB & $\mathrm{Y}=979,36-10,54 \mathrm{X}$ & $-0,50^{* *}$ \\
Borracha seca x V & $\mathrm{Y}=985,70-7,63 \mathrm{X}$ & $-0,43^{*}$ \\
\hline \multicolumn{3}{c}{$20-40 \mathrm{~cm}$} \\
Borracha seca x pH & $\mathrm{Y}=1.973,69-254,52 \mathrm{X}$ & $-0,56^{* *}$ \\
Borracha seca x Ca+Mg & $\mathrm{Y}=975,09-17,46 \mathrm{X}$ & $-0,43^{*}$ \\
Borracha seca X SB & $\mathrm{Y}=978,38-17,03 \mathrm{X}$ & $-0,42^{*}$ \\
Borracha seca x V & $\mathrm{Y}=978,10-8,77 \mathrm{X}$ & $-0,43^{*}$ \\
\hline \multicolumn{3}{c}{$40-60 \mathrm{~cm}$} \\
Borracha seca x pH & $\mathrm{Y}=1.799,62-210,10 \mathrm{X}$ & $-0,52^{* *}$ \\
Borracha seca x H + Al & $\mathrm{Y}=445,68+10,36 \mathrm{X}$ & $0,43^{*}$ \\
Borracha seca x C & $\mathrm{Y}=291,39+96,66 \mathrm{X}$ & $0,45^{*}$ \\
\hline
\end{tabular}

* e **Significativo a $5 \%$ e a $1 \%$ de probabilidade, respectivamente. ção dos Nitossolos, que apresentaram teores muito altos, nas três profundidades. Constatou-se um decréscimo nos teores de $\mathrm{Ca}^{2+}+\mathrm{Mg}^{2+}$, à medida que a profundidade aumentava, evidenciando a aplicação de calcário dolomítico nas áreas. Houve respostas significativas e negativas quanto às relações entre produção de borracha seca e teores de $\mathrm{Ca}^{2+}+\mathrm{Mg}^{2+}$ no solo, nas profundidades de $0-20$ e $20-40 \mathrm{~cm}$ (Tabela 2). Assim como para outras espécies, observou-se o efeito antagônico da relação $\mathrm{Ca}^{2+}+\mathrm{Mg}^{2+} / \mathrm{K}$, provavelmente, em razão da competição entre esses íons no solo (Bolton, 1964). Essa relação associada ao déficit hídrico pode estar gerando um efeito sinérgico negativo em relação à absorção de $\mathrm{K}$, com consequiências na redução da produção de borracha seca.

Segundo Maia (1999), o excesso de Ca no solo provoca a pré-coagulação do látex, ainda durante o escorrimento, ao longo do corte de sangria, diminuindo drasticamente a produção, enquanto o excesso de $\mathrm{Mg}$ reduz a estabilidade mecânica do látex centrifugado, exigindo um procedimento específico, na usina, para reduzir o seu teor antes da centrifugação.

De modo geral, $80 \%$ dos solos dos seringais apresentaram soma de bases trocáveis baixa, assim como $84 \%$ apresentaram baixa porcentagem de saturação por bases. As relações entre esses atributos e a produção de borracha seca foram negativas e significativas nas profundidades de $0-20$ e $20-40 \mathrm{~cm}$ (Tabela 2), provavelmente, em decorrência dos altos teores de $\mathrm{Ca}^{2+}+\mathrm{Mg}^{2+}$ nestas camadas e do tipo de solo. A capacidade de troca catiônica efetiva dos solos decresceu com a profundidade, variando de média a alta, e os teores altos foram encontrados na camada superficial do solo.

Quanto aos micronutrientes disponíveis no solo, as informações no Estado de Minas Gerais são escassas, apesar da deficiência freqüente de B e Zn em várias culturas (Comissão de Fertilidade do Solo do Estado de Minas Gerais, 1999). No presente trabalho, não foram observados sintomas visuais de deficiências de micronutrientes.

Como ocorreu nos solos, os resultados das análises foliares realizadas nos dois anos também apresentaram pouca variação. Por causa disso, preferiuse trabalhar com valores médios. Os teores mínimos, 
médios e máximos dos nutrientes encontrados nas folhas, bem como a porcentagem de seringais encontrados acima, abaixo e dentro dos limites da faixa adequada para o desenvolvimento satisfatório da cultura, segundo Murbach (1997) encontram-se na Tabela 3.

Usando as relações definidas por Beaufils (1957), dos seringais avaliados, apenas $28 \%$ apresentaram as relações N/P em equilíbrio nutricional, $44 \%$ delas tendendo ao desequilíbrio e $28 \%$ fortemente desequilibradas, com carência de $\mathrm{N}$ e excesso de fósforo. Esses dados estão em conformidade com Murbach (1997), que considera que $80 \%$ dos seringais encontram-se em desequilíbrio nutricional, uma vez que os teores foliares de $\mathrm{N}$ estão abaixo da faixa considerada adequada (Tabela 3 ) e que, apesar dos solos possuírem, em sua grande maioria, baixos teores de $\mathrm{P}$, as plantas mostraram-se eficientes na sua absorção, já que, nas folhas, $84 \%$ dos seringais apresentaram teores desse nutriente na faixa adequada.

Segundo Beaufils (1957), dos seringais estudados, no que se refere às relações N/K, $40 \%$ estão em equilíbrio nutricional e $60 \%$ apresentam excesso de Ke deficiência de nitrogênio. Murbach (1997) considera a deficiência tanto do $\mathrm{N}$ como do K e confirma que $88 \%$ dos seringais apresentam baixos teores deste último nutriente. A correlação entre a produção de borracha seca e os teores dos dois nutrientes, nas folhas, foi positiva e significativa, enfatizando a importância deles na nutrição da seringueira (Tabela 4). Estes resultados demonstram a necessidade de um suprimento equilibrado desses dois nutrientes, considerando-se que a deficiência deles no solo se refletiu nas folhas e, conseqüentemente, na produção. A maior parte dos seringais estudados encontra-se implantada em áreas de solos exauridos por décadas de cultivo de café e/ou pastagens, o que, associado a chuvas concentradas em curto período do ano, resulta em acentuado empobrecimento desses solos.

Segundo Beaufils (1957), com respeito às relações $\mathrm{K} / \mathrm{P}$, somente $12 \%$ encontram-se em equilíbrio nutricional enquanto $88 \%$ apresentam-se com deficiência de potássio. De acordo com o mesmo autor, quanto às relações $\mathrm{S} / \mathrm{P}, 62 \%$ encontram-se em situação normal e 38\%, com excesso de enxofre. Resultados semelhantes foram encontrados quando os teores de $\mathrm{S}$ foram analisados, isoladamente, pois, segundo Murbach (1997), com base neles, 68\% dos seringais estavam na faixa adequada e $32 \%$, acima. Estes resultados refletem o efeito de adições desse nutriente, provavelmente, por causa das adubações com superfosfato simples.

Os teores de Ca nas folhas variaram entre os seringais, uma vez que $40 \%$ situaram-se na faixa adequada e $40 \%$, abaixo dela (Tabela 3). Os $20 \%$ restantes apresentaram teores elevados do nutriente, provavelmente, por se tratarem dos Nitossolos, que tam-

Tabela 3. Teores mínimo, médio e máximo dos nutrientes encontrados em folhas de seringueira, e porcentagem de seringais abaixo, acima e na faixa adequada, do clone IAN 873, implantados na região da Zona da Mata de Minas Gerais (médias dos anos de 1997 e 1998).

\begin{tabular}{|c|c|c|c|c|c|c|}
\hline \multirow[t]{3}{*}{ Nutrientes } & \multicolumn{3}{|c|}{ Teores } & \multicolumn{3}{|c|}{ Faixa de suficiência } \\
\hline & Mínimo & Médio & Máximo & Abaixo & Adequado & Acima \\
\hline & ---- & $\left(\mathrm{g} \mathrm{kg}^{-1}\right.$ & - & & --- (\%)--- & - \\
\hline $\mathrm{N}$ & 18,9 & 23,5 & 27,3 & 80 & 20 & - \\
\hline $\mathrm{P}$ & 1,4 & 2,0 & 2,5 & 4 & 84 & 12 \\
\hline $\mathrm{K}$ & 4,4 & 6,5 & 14,0 & 88 & 12 & - \\
\hline $\mathrm{Ca}$ & 3,2 & 8,8 & 13,6 & 40 & 40 & 20 \\
\hline $\mathrm{Mg}$ & 1,9 & 4,1 & 6,0 & - & 56 & 44 \\
\hline \multirow[t]{2}{*}{$\mathrm{S}$} & 2,0 & 2,3 & 3,2 & - & 68 & 32 \\
\hline & \multicolumn{3}{|c|}{ - } & \multicolumn{3}{|c|}{ - } \\
\hline $\mathrm{Fe}$ & 86 & 158 & 271 & - & 100 & - \\
\hline $\mathrm{Mn}$ & 194 & 499 & 1.230 & - & 80 & 20 \\
\hline $\mathrm{Cu}$ & 5 & 12 & 18 & 24 & 72 & 4 \\
\hline $\mathrm{Zn}$ & 29 & 43 & 75 & - & 84 & 16 \\
\hline B & 17 & 32 & 52 & 12 & 88 & - \\
\hline
\end{tabular}


Tabela 4. Equações de regressão e coeficientes de correlação (r) entre a produção de borracha seca (Y) e os teores de nutrientes $(\mathrm{X})$ encontrados em folhas de seringueira do clone IAN 873, implantado na região da Zona da Mata de Minas Gerais.

\begin{tabular}{llc}
\hline Variáveis & \multicolumn{1}{c}{ Equação } & $\mathrm{r}$ \\
\hline $\mathrm{Y} \times \mathrm{X}(\mathrm{Cu})$ & $\mathrm{Y}=472,35+34,49 \mathrm{X}$ & $0,62^{* *}$ \\
$\mathrm{Y} \times \mathrm{X}(\mathrm{N})$ & $\mathrm{Y}=-52,03+39,43 \mathrm{X}$ & $0,42^{*}$ \\
$\mathrm{Y} \times \mathrm{X}(\mathrm{K})$ & $\mathrm{Y}=563,77+47,94 \mathrm{X}$ & $0,48^{*}$ \\
$\mathrm{Y} \times \mathrm{X}(\mathrm{Ca})$ & $\mathrm{Y}=1.237,74-41,39 \mathrm{X}$ & $-0,51^{* *}$ \\
\hline
\end{tabular}

* e **Significativo a $5 \%$ e a $1 \%$ de probabilidade, respectivamente.

bém mostraram altos teores do nutriente. Como ocorreu no solo, o coeficiente de correlação entre o teor do nutriente e a produção de borracha seca também foi negativo e significativo (Tabela 4). Quanto aos teores de $\mathrm{Mg}, 56 \%$ apresentaram-se na faixa adequada e 44\%, acima (Tabela 3).

Os resultados encontrados sugerem a necessidade de se reduzir esses nutrientes nas fórmulas de adubação, na região, visando diminuir o custo de manutenção dos seringais.

Todas as áreas estudadas apresentaram teores de Fe dentro da faixa adequada (Tabela 3 ). Os seringais que apresentaram os teores mais baixos do nutriente, mesmo na faixa adequada, mostraram altos teores de $\mathrm{S}$ e magnésio. Os teores de $\mathrm{Mn}$ mostraram resultados semelhantes. Os teores foliares de $\mathrm{Cu}$ variaram pouco: $72 \%$ situaram-se na faixa adequada e $24 \%$, abaixo (Tabela 3). Mesmo com coeficiente de correlação significativo, provavelmente este nutriente não deve ter influenciado a produção de borracha seca (Tabela 4).

No caso do Zn, $84 \%$ estavam na faixa adequada e apenas os seringais instalados nos Nitossolos encontravam-se acima da mesma. A maior parte deles (88\%) não apresentou problemas com B, uma vez que em apenas $12 \%$, os teores encontravam-se abaixo da faixa adequada. Interessante observar que os seringais com baixos níveis desse nutriente situamse em solos nitossólicos, destacando-se por níveis mais elevados dos nutrientes $\mathrm{Ca}, \mathrm{Mg}$ e zinco.

\section{Conclusões}

1. A maioria dos seringais da Zona da Mata de Minas Gerais encontra-se instalada em Latossolos de baixa fertilidade, apresentando fortes desequilíbrios nutricionais.
2. O clone IAN 873 apresenta maior produção de borracha seca nos Latossolos que nos Nitossolos.

3. Os altos teores de cálcio e magnésio no solo e nas folhas, com reflexos negativos na produção de borracha, sugerem redução da calagem e da adubação contendo os dois nutrientes.

4. A análise foliar como complemento da análise do solo evidencia desequilíbrios nutricionais, principalmente, no que se refere aos baixos teores de N, Ke cobre.

5. A produção de borracha seca é menor em seringais que apresentam baixos teores de $\mathrm{N}$ e $\mathrm{K}$ nos solos e nas folhas.

\section{Referências}

BATAGLiA, O. C.; CARDOSO, M.; CARRETERO, M. V. Situação nutricional de seringais produtivos no Estado de São Paulo. Bragantia, Campinas, v. 47, n. 1, p. 109-123, 1988.

BATAGLIA, O. C.; SANTOS, W. R.; GONÇALVES, P. S.; SEGNINI JUNIOR, I.; CARDOSO, M. Efeito da adubação NPK sobre o período de imaturidade da seringueira. Bragantia, Campinas, v. 58, n. 2, p. 363-374, 1999.

BATAGLiA, O. C.; SANTOS, W. R.; IGUE, T.; GONÇALVES, P. S. Resposta da seringueira clone RRIM 600 à adubação NPK em solo Podzólico VermelhoAmarelo. Bragantia, Campinas, v. 57, p. 367-377, 1998.

BEAUFILS, E. R. Pesquisa de uma exploração racional da Hevea após um diagnóstico fisiológico demorado sobre a análise mineral de diversas partes da planta. Fertilité, Paris, v. 3, p. 27-38, 1957.

BOLTON, J. The manuring and cultivation of Hevea brasiliensis. Journal of the Science of Food and Agriculture, London, v. 15, p. 1-8, 1964.

CAMARGO, M. N.; KLAMT, E.; KAUFFMAN, J. H. Sistema brasileiro de classificação de solos. Boletim Informativo da Sociedade Brasileira de Ciência do Solo, Campinas, v. 12, n. 1, p. 11-33, 1987.

COMISSÃO DE FERTILIDADE DO SOLO DO ESTADO DE MINAS GERAIS (Lavras, MG). Recomendações para o uso de corretivos e fertilizantes em Minas Gerais: 5a aproximação. Viçosa, MG, 1999. 359 p.

CUNHA, T. J. F.; BLANCANEAUX, P.; CALDERANO FILHO, B.; CARMO, C. A. F. de S. do; GARCIA, N. C. P.; 
LIMA, E. M. B. Influência da diferenciação pedológica no desenvolvimento da seringueira no município de Oratórios, MG. Pesquisa Agropecuária Brasileira, Brasília, v. 35, n. 1, p. 145-155, jan. 2000.

EMBRAPA. Centro Nacional de Pesquisa de Solos (Rio de Janeiro, RJ). Manual de métodos de análise de solo. 2. ed. Rio de Janeiro, 1997. 212 p. (Documentos, 1).

EMBRAPA. Centro Nacional de Pesquisa de Solos (Rio de Janeiro, RJ). Sistema brasileiro de classificação de solos. Brasília: Embrapa-SPI/Embrapa-CNPS, 1999. $412 \mathrm{p}$.

EMBRAPA. Serviço Nacional de Levantamento e Conservação de Solos (Rio de Janeiro, RJ). Manual de métodos de análise do solo. Rio de Janeiro, 1979. Não paginado.

FALCÃO, N. P. de S. Adubação N P K afetando o desenvolvimento do caule da seringueira e parâmetros fisiológicos do látex. 1996. 134 f. Tese (Doutorado em Solos e Nutrição de Plantas) - Escola Superior de Agricultura Luiz de Queiroz, Piracicaba, 1996.

GUHA, M. M.; NARAYANAN, R. Variations in leaf nutrient status in relation to soil type. Journal of the Rubber Research Institute of Malaysia, Kuala Lumpur, v. 21, p. 225-239, 1969.

INSTITUTO DA POTASSA \& FOSFATO (Piracicaba, SP). Manual internacional de fertilidade do solo. Tradução e adaptação de Alfredo Scheid Lopes. 2. ed. rev. e ampl. Piracicaba: Potafos, 1998. 177 p.

KITAMURA, M. C. Influência dos níveis de nitrogênio, fósforo, potássio e magnésio no desenvolvimento da seringueira jovem (Hevea brasiliensis Muell. Arg.) em um solo sob cerrado de Mato Grosso do Sul. 1992. 90 f. Dissertação (Mestrado em Fitotecnia) - Escola Superior de Agricultura de Lavras, Lavras, 1992.
LEMOS, R. C. de; SANTOS, R. D. dos. Manual de descrição e coleta de solos no campo. 3. ed. Campinas: Sociedade Brasileira de Ciência do Solo/Embrapa-CNPS, 1996. $83 \mathrm{p}$.

MAIA, F. Z. A borracha bruta como matéria prima para a usina de beneficiamento. In: CICLO DE PALESTRAS SOBRE A HEVEICULTURA PAULISTA, 1., 1998, Barretos. Anais... Barretos: Secretaria de Agricultura e Abastecimento/Associação Paulista de Produtores e Beneficiadores de Borracha, 1999. p. 201-224.

MURBACH, M. R. Efeitos de níveis de nitrogênio, fósforo e potássio no desenvolvimento, produtividade de borracha seca e exportação de nutrientes pela seringueira. 1997. 94 f. Dissertação (Mestrado em Solos e Nutrição de Plantas) - Escola Superior de Agricultura Luiz de Queiroz, Piracicaba, 1997.

PEREIRA, A. V.; PEREIRA, E. B. C. Adubação de seringais de cultivo na Amazônia: primeira aproximação. Manaus: Embrapa-CNPSD, 1986. 32 p. (Circular Técnica, 8).

RAIJ, B. van. Técnicas de avaliação da fertilidade do solo e estabelecimento de níveis de adubação. In: ___ Avaliação da fertilidade do solo. Piracicaba: Potafos, 1981. p. 49-74.

SETZER, J. Contribuição para o estudo do clima do Estado de São Paulo. São Paulo: Escolas Profissionais Salesianas, 1946. 239 p.

SILVA, F. C. da. (Org.). Manual de análises químicas de solos, plantas e fertilizantes. Brasília: Embrapa-SCT, 1999. $370 \mathrm{p}$.

VETTORI, L. Métodos de análise de solos. Rio de Janeiro: Ministério da Agricultura, 1969. 24 p. (Boletim Técnico, 7).

VITTI, G. C. Avaliação e interpretação do enxofre no solo e na planta. Jaboticabal: Funep, 1989. 37 p. 